\title{
Roots and Leaf Extracts of Dipsacus fullonum L. and Their Biological Activities
}

\author{
Jan Oszmiański ${ }^{1}$, Aneta Wojdyło ${ }^{1, * \mathbb{C}}$, Piotr Juszczyk ${ }^{2} \mathbb{C}$ and Paulina Nowicka ${ }^{1}$ \\ 1 Department of Fruit, Vegetable and Plant Nutraceuticals Technology, Wrocław University of Environmental \\ and Life Sciences, 37 Chełmońskiego Street, 51-630 Wrocław, Poland; jan.oszmianski@upwr.edu.pl (J.O.); \\ paulina.nowicka@upwr.edu.pl (P.N.) \\ 2 Department of Biotechnology and Food Microbiology, Wrocław University of Environmental and Life \\ Sciences, 37 Chełmońskiego Street, 51-630 Wrocław, Poland; piotr.juszczyk@upwr.edu.pl \\ * Correspondence: aneta.wojdylo@upwr.edu.pl
}

Received: 2 November 2019; Accepted: 3 January 2020; Published: 8 January 2020

\begin{abstract}
The aim of the study was to identify and evaluate the content of iridoids and phenolic compounds in the leaves and roots of Dipsacus fullonum L. They were identified and quantified by UPLC-PDA-MS/MS. Five iridoid compounds (loganic acid, loganin, sweroside, cantleyoside, and sylvestroside III) were identified in Dipsacus fullonum L. leaves and roots. Seven phenolic acids and three flavones were identified in the leaves, and seven phenolic acids were detected in the roots. The leaves contained more iridoids and phenolic compounds than the roots. We also evaluated the antimicrobial (anti-bacterial and anti-yeast), antioxidant (ORAC methods), and antiacetylcholinesterase (AChE) activities of Dipsacus fullonum L. leaves and roots. Leaf extract demonstrated the strongest antioxidant activity, but roots showed stronger antiacetylcholinesterase activity than leaves. The study also confirmed antibacterial activity of root-derived compounds against Staphylococcus aureus DSM 799 and Escherichia coli ATCC 10536.
\end{abstract}

Keywords: Dipsacus fullonum L.; irydoids; polyphenols; UPLC-PDA-QTof-MS/MS; anti-bacterial; anti-yeast; anti-oxidant; anti-acetylcholinesterase activities

\section{Introduction}

With a long history of cultivation, consumption, and trade, the everlasting quest for health-promoting and disease-preventing agents in the developed world has changed people's view of plant sources. Plants have been globally utilized since antiquity for flavoring, coloring, and preserving foods and also for food production, cosmetic, and medicinal purposes [1]. Traditional medicine uses roots and leaves as they are rich in bioactive compounds and excellent sources of compounds such as triterpenes, iridoids, xanthones, carotenoids, and benzophenones [2-4]. Polyphenolic compounds such as phenolic acids and flavonoids are still among the crucial compounds exhibiting high antioxidant activity. They are common plant secondary metabolites necessary not only in plant physiological processes but also exerting positive effects on human health as antioxidants. Biological properties of these compounds were demonstrated in vitro and in vivo and they include antioxidant [5], antifungal, antimicrobial [6], antidiabetic [7], anti-inflammatory [5,8], antipyretic, analgesic, and immunomodulatory activity [2].

Apart from phenolics, other compounds such as iridoids have attracted increasing attention. Iridoids belong to bicyclic monoterpenes with a cyclopentane-pyran ring in their structure, and they mostly exist in plants as iridoid glycosides, linked through $\beta$-hemiacetal bond to C1. Basic iridoids isolated from plants are loganic acid, loganin, secologanin, sweroside, oleuropein, and pentoside of loganic acid. Iridoids are biologically active compounds with different activities. 
Their anti-inflammatory, neuroprotective, hypotensive, antibiotic, and sedative properties depend on their structure [9-11]. A hydrolyzed product of the iridoids, harpagoside andharpagide, more effectively inhibits cyclooxygenase- 2 than the other natural metabolites. Plants rich in this type of monoterpene include Apocynaceae, Lamiaceae, Loganiaceae, Rubiaceae, Scrophulariaceae and Verbenaceae [12]. The compounds are found mainly in the leaves and young stems and hardly ever in fruits. Some iridoids were identified in the leaves of Sambucus ebulus [13] and in Penstemon barbatus, Castilleja tenuiflora, Cresentia alata, and Vitex mollis [11].

The referenced studies reflect the increasing interest in finding plant resources with high biological activity for scientific research and industrial applications.

Dipsacus fullonum L. is a flowering plant commonly known as teasel or wild teasel. It is a 1-2.5 m tall, herbaceous, biennial plant with prickly stems, a distinctive cone-shaped flower head, and wrinkled, downward-pointing prickly leaves. D. fullonum has been used to treat several diseases, like fibromyalgia, bone fracture, lime disease, and especially cancer and Alzheimer's disease $[14,15]$. Additionally, it has cytoprotective properties, is capable of inhibiting HIV-1 reverse transcriptase, and may act as an antibacterial, anti-inflammatory, and anti-complement agent, as well as a growth stimulant in osseous cells $[14,15]$. Root extracts of D. sylvestris, a plant belonging to the Dipsacus genus, were active against Borrelia burgdorferi s.s., which causes Lyme disease [14,16]. The plant roots of D. ferox and D. asperoides were reported to contain iridoid glycosides and phenolic compounds [17-19]. However, there are no data on the presence of bioactive compounds in D. fullonum leaves, and no information is available also about antioxidants and antidiabetic potential or antibacterial activity.

Therefore, the aim of this study was to identify and determine the content of iridoids and polyphenolics in the leaves and roots of Dipsacus fullonum L. by means of UPLC-PDA-QTof-MS/MS and to evaluate their biological activity, especially antioxidant, anticholinesterase, antidiabetic. The potential toxicity of the leaves and roots extracts towards microorganisms was evaluated using the antimicrobial test carried out against bacterial strains (as Bacillus subtilis B5, Escherichia coli ATCC 10536, Pseudomonas aeruginosa DSM 939, Pseudomonas fluorescens W1, Staphylococcus aureus DSM 799) and against selected yeast (Candida famata AII4b, Candida tropicalis ATCC 60557, Candida sphaerica FII7A, Saccharomyces cerevisiae SV30, Yarrowia lipolytica PII6a). To our knowledge, this is the first report comparing polyphenolic and iridoid compounds and bioactivity of the leaves and roots.

\section{Results}

\subsection{Identification of Iridoids and Phenolics in D. fullonum L. Leaves and Roots}

Table 1 shows qualitative identification of the compounds found in D. fullonum L. leaves and roots. In analyzed plant materials 15 compounds belonging to two groups were identified-monoterpenes (iridoids) and polyphenols (flavons and phenolic acids).

UPLC-PDA-QTof-MS/MS for monoterpenes singled out five compounds as iridoids, two of which were positively identified by comparison with standards if they available and the others were tentatively described by their spectra of individual spectral data of peaks (UV/Vis, MS), elution order, UPLC retention times, and by comparison with literature data.

Peak 1 corresponded to characteristic molecular formula of $\mathrm{C}_{16} \mathrm{H}_{24} \mathrm{O}_{10}$. After deprotonated molecule the ion at $m / z 213$ was found after loss of glucose (162 Da). Additionally, comparison with a standard peak 1 was identified as loganic acid.

Peak 2, with a $[\mathrm{M}-\mathrm{H}]^{-}$ion at $m / z 389$, and in the MS/MS spectrum with the ions at $m / z 227$ that were yielded via a neutral loss of glucose (162 Da) from the deprotonated molecule $[\mathrm{M}-\mathrm{H}]^{-}$of peak 2, was identified as loganin based on comparison with a reference compound.

Peak 3 had a major fragment ion at $m / z 195$ indicating the presence of a glucose unit (162 Da) in its structure. By comparison with the available standard and reference [20], this compound was tentatively identified as sweroside. 
Peak 4 after a loss of glucose unit (162 Da) presented main mass as $[\mathrm{M}-\mathrm{H}]^{-}$ion at $\mathrm{m} / z \mathrm{z} 45$, and $m / z$ 583. This compound was tentatively identified as cantleyoside, which is in agreement with literature data [19].

Peak 5 presented the characteristic of a $[\mathrm{M}-\mathrm{H}]^{-}$ion at $\mathrm{m} / \mathrm{z} 583$, and $\mathrm{m} / \mathrm{z} 421$ after loss of glucose (162 Da). After comparison to the literature [15,21,22] this peak was identified as sylvestroside III.

All analyzed leaves and roots contained the same types of compounds. Some were previously identified in other plants, such as berry of blue honeysuckle [23] and fructus Corni [24]. The roots of $D$. asper were previously reported to contain such iridoid glucosides as loganin, lisianthioside, cantleyoside, triplostoside A, or 6-O- $\beta$-D-apiofuranosylsweroside [23], as well as loganic acid ethyl ester, loganin, cantleyoside and syringaresinol- $4^{\prime}, 4^{\prime \prime}-O-b i s-\beta$-D-glucoside $[25,26]$. The extent and content of iridoid compounds may vary relying on the growth period, year of harvest, geographic location, or cultivation method [27].

Table 1. LC-QTOF/MS analysis and quantification of iridoid and polyphenolic compounds (mg/g dry weight- $\mathrm{dw}$ ) in D. fullonum L. leaves and root.

\begin{tabular}{|c|c|c|c|c|c|c|c|c|}
\hline \multirow{2}{*}{ Peak No. } & \multirow{2}{*}{ Compound } & \multirow{2}{*}{$\underset{(\min )}{T_{R}}$} & \multirow{2}{*}{$\begin{array}{l}\lambda_{\max } \\
(\mathrm{nm})\end{array}$} & \multirow{2}{*}{$\begin{array}{l}\text { MS } \\
(m / z)\end{array}$} & \multirow{2}{*}{ MS/MS (m/z) } & \multicolumn{2}{|c|}{ Leaves } & \multirow{2}{*}{ Roots } \\
\hline & & & & & & 2017 & 2018 & \\
\hline \multicolumn{9}{|c|}{ Iridoids } \\
\hline 1 & Loganic acid & 3.86 & 240 & 375 & 213/191/169/151/119 & $2.60 \pm 0.11 b$ & $0.18 \pm 0.06 c$ & $5.27 \pm 0.67 a$ \\
\hline 2 & Loganin & 5.18 & 238 & 389 & $227 / 209$ & $0.64 \pm 0.02 b$ & $0.56 \pm 0.02 b$ & $3.02 \pm 0.23 a$ \\
\hline 3 & Sweroside & 5.30 & 238 & 357 & $195 / 125$ & $0.67 \pm 0.11 \mathrm{a}$ & $0.35 \pm 0.01 b$ & $0.45 \pm 0.06 b$ \\
\hline 4 & Cantleyoside & 8.24 & 236 & 745 & 583 & $2.38 \pm 0.21 c$ & $11.83 \pm 1.11 b$ & $21.41 \pm 2.13 a$ \\
\hline 5 & Sylvestroside III & 9.14 & 240 & 583 & 421 & $34.80 \pm 3.21 \mathrm{a}$ & $19.14 \pm 3.21 b$ & $3.17 \pm 0.66 c$ \\
\hline & Total iridoids & & & & & 41.09 & 32.06 & 33.32 \\
\hline \multicolumn{9}{|c|}{ Polyphenol } \\
\hline 1 & Neochlorogenic acid & 3.54 & 325 & 353 & 191 & $0.52 \pm 0.1 \mathrm{a}$ & $0.48 \pm 0.05 a$ & $0.24 \pm 0.02 b$ \\
\hline 2 & Chlorogenic acid & 5.02 & 325 & 353 & 191 & $10.98 \pm 2.01 b$ & $28.44 \pm 2.54 a$ & $6.47 \pm 0.45 c$ \\
\hline 3 & Cryptochlorogenic acid & 5.27 & 325 & 353 & 191 & $0.86 \pm 0.23 a$ & $0.63 \pm 0.04 a$ & $0.30 \pm 0.02 b$ \\
\hline 4 & Caffeoylquinic acid & 5.56 & 325 & 353 & 191 & $0.40 \pm 0.05 b$ & $1.15 \pm 0.12 \mathrm{a}$ & $0.07 \pm 0.01 c$ \\
\hline 5 & $\begin{array}{c}\text { Apigenin-6-C-glucoside- } \\
\text { 7-O-glucoside (Saponarin) } \\
\text { Luteolin }\end{array}$ & 5.74 & 334 & 593 & $431 / 311$ & $5.74 \pm 0.12 b$ & $8.54 \pm 1.43 a$ & $0.02 \pm 0.01 c$ \\
\hline 6 & $\begin{array}{l}\text { 8-C-D-glucopiranoside } \\
\text { (Orientin) }\end{array}$ & 5.87 & 347 & 447 & 327 & $0.42 \pm 0.03 b$ & $4.65 \pm 1.09 a$ & nd * \\
\hline 7 & $\begin{array}{l}\text { Apigenin-6-C-glucoside } \\
\text { (Saponaretin) }\end{array}$ & 6.78 & 339 & 431 & 311 & $1.17 \pm 0.12 b$ & $2.99 \pm 0.38 a$ & nd \\
\hline 8 & 3,5-Dicaffeoylquinic acid & 10.79 & 326 & 515 & $353 / 191$ & $2.78 \pm 0.51 b$ & $3.96 \pm 0.32 a$ & $3.77 \pm 0.34 a$ \\
\hline 9 & Di-caffeoylquinic acid isomer & 11.10 & 326 & 515 & $353 / 191$ & $0.17 \pm 0.11 \mathrm{a}$ & $0.21 \pm 0.03 \mathrm{a}$ & $0.17 \pm 0.02 a$ \\
\hline \multirow[t]{2}{*}{10} & Di-caffeoylquinic acid isomer & 11.45 & 326 & 515 & $353 / 191$ & $0.38 \pm 0.04 b$ & $0.53 \pm 0.10 \mathrm{~b}$ & $1.39 \pm 0.09 a$ \\
\hline & Total polyphenols & & & & & 23.42 & 51.58 & 12.43 \\
\hline
\end{tabular}

* nd-not detected; $a, b, c-$ different letters in the same column denote a significant difference among varieties according to Tukey's test, $p<0.05$.

D. fullonum L. leaves and roots contained seven derivatives of phenolic acids, i.e., caffeoylquinic acid derivatives (Table 1 ). Four of them revealed the same $[\mathrm{M}-\mathrm{H}]^{-}$at $m / z 353$ and $\lambda_{\max }=325$ but it was derived from different compounds, i.e., neochlorogenic (1), chlorogenic acid (2), cryptochlorogenic (3), and one caffeoylquinic (4) acid. In addition, three di-caffeoylquinic acids (8-10) were identified with $[\mathrm{M}-\mathrm{H}]^{-}$at $\mathrm{m} / z 515$ with $\lambda_{\max }=326$. Cochromatographic standards for neochlorogenic, chlorogenic, cryptochlorogenic, and 3,5-dicaffeoylquinic acid were used to confirm the identity of these compounds. All of them were previously reported by other authors $[15,20,28]$. Caffeoylquinic acid is a phenolic acid very common in different parts of plants, especially 5-caffeoylquinic acid (chlorogenic acid). Analyzed D. fullonum leaves contained three flavons identified as apigenin and luteolin derivatives, according to their UV spectrum and MS fragmentation (Table 1). Roots contained only one of these flavons. Two peaks were identified as apigenin derivatives, $-6-C$-hexoside-7-O-hexoside (saponarin $-m / z 593$ and with $\lambda_{\max }=334 \mathrm{~nm}$ ) and $-6-C$-hexoside (saponaretin $-m / z 431$ and with $\lambda_{\max }=339 \mathrm{~nm}$ ). All these compounds exhibited MS/MS as [M-fragments of $C$-hexoside $]^{-} m / z 311$ typical of $C$-hexoside derivatives. The second flavon was a single luteolin derivative with MS/MS as characteristic $[\mathrm{M}-\mathrm{H}]^{-}$ $m / z 447$ and MS-. MS fragmentation $m / z 327$ with $\lambda_{\max }=347 \mathrm{~nm}$ of luteolin 8-C- $\beta$-D-glucopiranoside 
(orientin). The presence of some of these compounds was also suggested by Kowalczyk et al. [29] and Yang et al. [30].

\subsection{Quantification of Iridoid and Phenolic Compounds in D. fullonum L. Leaves and Roots}

Iridoid content is one of the most important indicators of biological activity in D. fullonum L. leaves and roots. Table 1 shows the content of iridoids in the investigated organs-leaves (two study years) and roots (one study year). They were the most abundant in the leaves collected in the first year $(41.09 \mathrm{mg} / \mathrm{g}$ dry weight-dw), and in the second year their content dropped by $22 \%$ and $19 \%$ in the leaves and roots, respectively. The content of individual iridoids was highly variable. The major iridoid in D. fullonum L. roots was cantleyoside that accounted for $64 \%$ of total iridoids, and the second was loganic acid that amounted to $16 \%$ of all compounds. The remaining iridoids in the root were sylvestroside III (10\%), loganin ( $9 \%)>>$ sweroside $(1 \%)$. A dominant iridoid in D. fullonum L. leaves was sylvestroside III that accounted for $85 \%$ of total iridoids in the leaves collected in 2017 and $60 \%$ in the leaves from 2018. Abundance of the other iridoids in the leaves was 6\% and 37\% in 2017 and 2018 for cantleyoside $>6 \%$ and $1 \%$ for loganic acid $>>2 \%$ and $1 \%$ for sweroside and for loganic. These results indicate that D. fullonum L. leaves collected in 2017 and 2018 may be, apart from commonly used roots, a useful source of biologically active compounds, such as iridoids.

High content of iridoids is beneficial, as they exhibit considerable biological activity. For example, loganic acid has strong anti-inflammatory properties [11]. In rabbits [31], loganic acid exhibited anti-inflammatory activity, diminished diet-induced dyslipidemia and atherosclerosis, and increased PPAR-a and PPAR-expression.

The observed differences between years are probably due to weather conditions in the harvest season and a degree of plant maturity, as suggested by Dinda et al. [9], Pieri et al. [13], and Yang et al. [32]. Kucharska et al. [27] showed that average content of iridoids in cornelian cherry, ranging from 86.91 to $493.69 \mathrm{mg} / 100 \mathrm{~g}$ fresh weight, strictly depended on cultivar and genotype, and the main compound was loganic acid.

Moreover, as presented in Table 1, D. fullonum leaves seem to be a much richer source of biologically active polyphenolic compounds than roots. The derivatives of apigenin and luteolin were only found in the leaves, and they were more abundant in those collected in 2017 than in 2018 (16.18 vs. $7.33 \mathrm{mg} / \mathrm{g}$, respectively). Derivatives of caffeic acid were detected in both leaves and roots (35.4 mg/g vs. $16.09 \mathrm{mg} / \mathrm{g}$, respectively) and were the most abundant in the leaves collected in 2018. Chlorogenic acid, known for its considerable biological activity, was a dominant phenolic acid in all samples. Shin et al. [33] reported that phenolic acids, especially chlorogenic acid, had potent antioxidant capacity and may inhibit DNA damage or increase the resistance of LDL to lipid peroxidation. These properties help to protect the human body against chronic non-communicable diseases, including obesity and diabetes. High concentration of chlorogenic acid is typical for fruits and their products [34]. Tandon et al. [35] showed that leaf and root extracts of A. parviflora, A. bracteosa, and T. quadrifarium contained such phenolic acids as protocatechuic, $p$-hydroxybenzoic, chlorogenic, and vanilic. Oszmiański and Wojdyło [36] detected only traces of phenolic acid derivatives (ellagic and gallic) and flavan-3-ols in the roots of Aruncus silvester and found that the roots of Potentilla alba, Geumrivale, and Waldsteiniageoides were rich in tannins but not in phenolic acids.

Previous studies demonstrated that the leaves of different berries (such as blackcurrant, bilberry, cranberry, and chokeberry) contained significantly more polyphenols than the fruits [34,37]. D. fullonum leaves collected in 2017 and 2018 contained about two and four times more total phenolics than roots. Moreover, Paliyath et al. [38] suggested that phenolic content in the leaves might vary depending on such factors as drought, temperature changes, pollution, UV light, and pathogen attack. Tattini et al. [39] confirmed a significant effect of these factors on the pool of antioxidants in Ligustrum vulgare leaves. Additionally, Wang and Lin [40] also suggested that polyphenol content in tissue might determine the degree of plant maturity. 


\subsection{Antimicrobial Activity}

Various fungal, bacterial, and viral species could cause plant, animal, and human diseases, hence the diseases of crops, food spoilage, or even food poisoning that could damage human health [38]. Thereby, it is important to extend natural effective antimicrobial agents. Our study analyzed antimicrobial activity of leaves and roots of $D$. fullonum. No information has been available on the antibacterial activity of this species. The extracts of $D$. fullonum leaves and roots were tested against selected bacteria B. subtilis B5, E. coli ATCC 10536, P. aeruginosa DSM 939, P. fluorescens W1, S. aureus DSM 799, and yeast species: C. famata AII4b, C. tropicalis ATCC 60557, C. sphaerica FII7a, S. cerevisiae SV30, and Y. lipolytica PII6a. The well diffusion test showed that E. coli ATCC 10536 and S. aureus DSM 799 were the most sensitive to root extract, and they were the only strains for which a zone of growth inhibition around the well was observed following treatment with the root extract.

Our results were cross-checked by the spot test-zones of inhibited growth of E. coli ATCC 10536 and S. aureus DSM 799 were found around dried root powder. We found no other positive or negative effects of plant materials in other tested bacteria and yeast. Taking these results into account, the effects of root and leaf extract on bacterial growth were assessed during cultivation in the Bioscreen $\mathrm{C}$ analyzer (Figure 1). The test showed significant differences in the bacterial growth depending on the strain and plant material. Optical density (OD) ranged from 0.1 to 1.75 . After $26 \mathrm{~h}$ of the experiment, the highest OD of 1.8 was observed in the culture of P. aeruginosa DSM 939 in medium containing aqueous leaves and root extracts. Based on the growth curves in control NB-medium of the tested bacteria, no effects (positive and negative) of extracts of $D$. fullonum L. on microbial growth was found. In more sensitive cells of B. subtilis B5 and P. fluorescens W1, OD values ranged from 1.0 to 1.2 but only in medium with root extract. The most conspicuous effect was observed for E. coli ATCC10536 and S. aureus DSM 799. The tested leaves and root extracts showed a strong antibacterial activity, with OD 0.1 and 0.2 , respectively. Based on the growth curves of the tested bacteria, no effects (positive or negative) of extract of $D$. fullonum L. leaves on microbial growth were found. Stanković et al. [41] evaluated different plant materials for their antimicrobial activity. They tested methanolic extracts against pathogenic bacteria isolated from human material. The extract from Laseritiumlati folium had the lowest inhibitory concentration against all the tested bacterial strains, i.e., E. coli, S. aureus, P. aeruginosa, and others. The extract from Angelica pancicii showed the strongest antimicrobial activity against $S$. pyogenes and P. aeruginosa and the extract from Angelica sylvestris against Streptococcus pyogenes and P. aeruginosa. The main factors molding the antimicrobial activity of plants involve the structure of main bioactive compounds and type of pathogen. In general, bacteria like gram-positive (i.e., Bacillus sp. and Staphylococcus sp.) are more sensitive than gram-negative ones (i.e., Escherichia and Pseudomonas) because their membranes are rich in lipopolysaccharides and form an impassable barrier to the bioactive compounds [42]. Additionally, antimicrobial activity is due to the presence of such bioactive compounds as polyphenolic [43-46] and essential oils as suggested by Aghraz et al. [47]. The antibacterial activity of flavonoids is well documented. Osawa et al. [43] estimated the activity of several different flavonoid compounds. They postulated that chalcones are more effective than flavanones or flavones, and the presence of hydroxyl groups at $2^{\prime}$ position are important for anti-staphylococcal activity of these compounds [43]. When methoxy groups were present, the antibacterial activity of flavonoids significantly reduced. Ohemeng et al. [44] tested 14 compounds belong to flavonoids, among which apigenin, quercetin, and 3,6,7,3', $4^{\prime}$-pentahydroxyflavone presented some inhibitory activity against bacteria such as Escherichia coli DNA gyrase and S. epidermidis, S. aureus, S. typhimurium, and Stenotrophomonas maltophilia. Bernard et al. [45] found that a glycosylated flavonol, quercetin-3-O-rutinoside, exhibited strong antibacterial activity against a permeable E. coli strain. Seow et al. [46] postulated that not only the main compounds but also trail compounds are responsible for antimicrobial activity. Nevertheless, the lack of antimicrobial function of some iridoid and polyphenolic compounds in D. fullonum leaves and roots does not exclude their pharmaceutical value. 
Leaves of Dipsacus fullonum L.

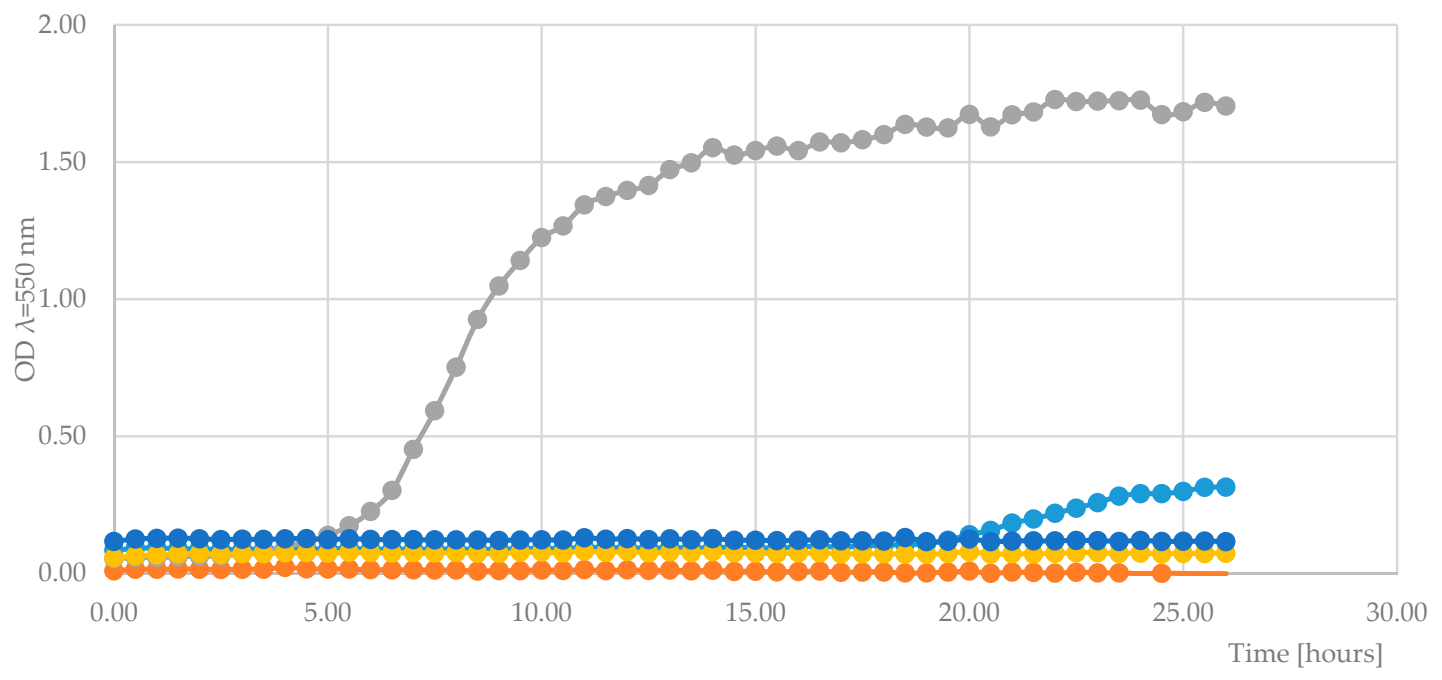

Root of Dipsacus fullonum L.

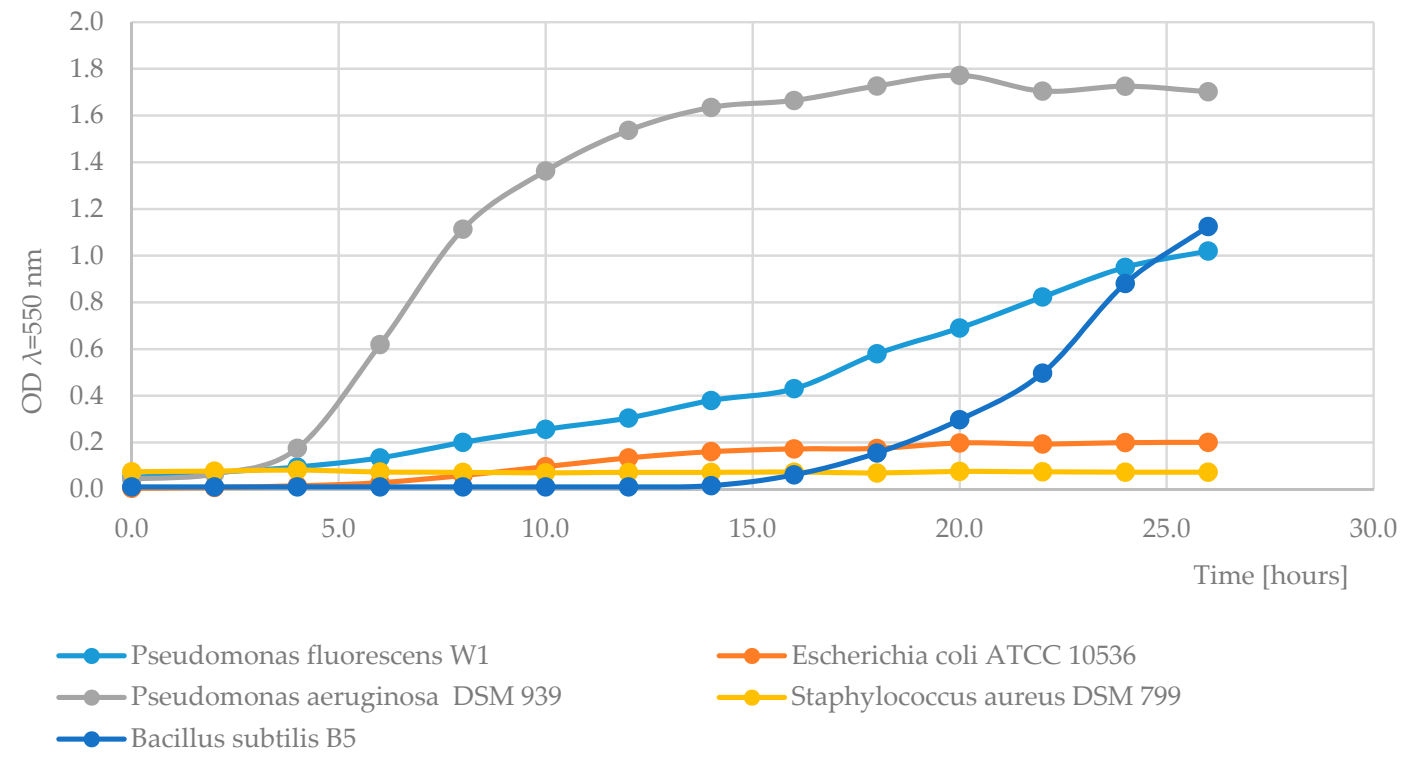

Figure 1. Effect of extract of leaves (top) and root (below) on bacterial growth in a micro-culture in a Bioscreen $\mathrm{C}$ apparatus $\left(t=26 \mathrm{~h}, \mathrm{~T}=30^{\circ} \mathrm{C}\right)$.

\subsection{Antioxidant and Antiacetylcholinesterase Activity}

Despite their traditional use, leaves are rarely used nowadays, in contrast to berry and fruits [2] or other plant organs such as roots or stems, which are considered food with significant health benefits conveyed by antioxidant activity.

We investigated the antioxidant activity (ORAC) and antiacetylcholinesterase (AChE) activity of leaves (from 2017) and roots. The effects of antioxidant present in the leaves and roots of D. fullonum were $14.78 \pm 0.94$ and $10.87 \pm 1.04 \mathrm{mmol} / 100 \mathrm{~g}$, respectively. High antioxidant activity of plants depends on many factors including the chemical profile of the analyzed material (qualitative and quantitative profiles of bioactive constituents) or plant organs. Our results show that the amount of iridoids weakly correlated with in vitro antioxidant activity measured by ORAC assay. This is due to the structure of iridoids that have none or only limited number of $\mathrm{OH}$ groups active in free radical scavenging [48]. Similar to our work, other authors reported poor hydrogen-donating ability 
of iridoids. Iridoids exhibit high biological activity, especially anti-inflammatory, and perform other biological functions [11,30]. Their antioxidant activity is modulated by phenolic compounds, especially by high content of caffeoylquinic acids.

Nowadays, the search for new sources of effective acetylocholinoesterase inhibitors for the treatment of neurodegenerative disorders such as Alzheimer's disease is extremely important, as acetylcholinesterase catalyzes hydrolysis of a neurotransmitter acetylcholine that terminates signaling events across cholinergic synapses, including those of neuromuscular functions. Some studies suggest that dietary supplements with antioxidants and free radical scavengers may display benefits in slowing the mild cognitive impairment of Alzheimer's disease [49]. Our results for anti-AChE enzymes were similar, and the roots of $D$. fullonum L. exhibited stronger inhibitory effect against AChE than leaves ( $47.14 \pm 0.05$ vs. $43.89 \pm 0.03 \%$, respectively). This effect may be explained, similar to as antioxidant activity, by the presence of biologically active compounds.

Bivar Roseiro et al. [50] reported that flavonoids with a free $\mathrm{OH}$-group at $\mathrm{C} 3$ are more effective inhibitors than their $\mathrm{C} 3-\mathrm{OH}$ glycosylated counterparts and those having no $\mathrm{C} 3-\mathrm{OH}$ group, such as luteolin and apigenin. However, the roots we investigated did not contain luteolin or apigenin. Therefore, we suppose the observed effects were due to phenolic acids or iridoids or other chemical constituents, including triterpene saponins and alkaloids identified in the roots of $D$. asper [15]. Other research [49] also shows that many plants rich in natural antioxidants have been proposed as alternative therapeutic agents for Alzheimer's disease. Ji et al. [26] showed that some iridoids isolated from the roots of $D$. asper exhibited a moderate neuroprotective activity against $\mathrm{A} \beta_{25-35}$-induced cell death in PC12 cells.

\section{Materials and Methods}

\subsection{Reagents and Standards}

Acetonitrile, formic acid, methanol, loganin, and loganic acid were purchased from Sigma-Aldrich (Steinheim, Germany). Chlorogenic, neochlorogenic, cryptochlorogenic, 3,5-dicaffeoylquinic acids, and luteolin- and apigenin-7-O-glucoside were purchased from Extrasynthese (Lyon, France).

\subsection{Plant Material}

Dipsacus fullonum L. roots and leaves from the first and second year of vegetation were obtained from a private garden in Chmęntowo (52 $\left.56^{\prime} 02.0^{\prime \prime} \mathrm{N} 17^{\circ} 46^{\prime} 15.9^{\prime \prime} \mathrm{E}\right)$, Pomerania, Poland. The raw material was collected in October 2017 (leaves and root) and 2018 (leaves). The leaves and roots were dried in a freeze dryer Alpha 1-4 LSC (Christ, Osterode, Germany). Then, they were pulverized by crushing with a closed laboratory mill (A.11; IKA, Staufen, Germany), and obtained powder was kept in a refrigerator $\left(-80^{\circ} \mathrm{C}\right)$ until the extract preparation.

\subsection{Extraction Procedure for Polyphenolic, Antioxidant as ORAC Method, and Anti-Acetylcholinesterase Activity Analysis}

Dried powdered samples of roots and leaves were extracted with $50 \%$ methanol. The extraction was performed twice via an incubation for 20 min under sonication with shaking (Sonic 6D, Polsonic, Warsaw, Poland), then the sample was centrifuged at $19,000 \times g$ for $10 \mathrm{~min}$, and the supernatant was filtered through a hydrophilic PTFE $0.20 \mu \mathrm{m}$ membrane (Millex Samplicity Filter, Merck, Darmstadt Germany) before analysis. The content of iridoids and polyphenolics was determined by means of ultra-performance liquid chromatography-photodiode array detector-mass spectrometry (UPLC-PDA-QTof-MS/MS) method. All extractions were carried out in triplicate. 


\subsection{Identification and Quantification of Iridoids and Phenolic Compounds by the UPLC-PDA-QTof- MS/MS Method}

An ACQUITY Ultra Performance LC system (Waters Corp., Milford, CT, USA) equipped with a photodiode array detector (PDA), a binary solvent manager, and a mass detector G2 Q-Tof micro mass spectrometer (Waters Corp., Manchester, UK) equipped with an electrospray ionization (ESI) source operating in negative and positive mode were used for identification and quantification of polyphenols and iridoids compounds [33,35,51,52]. Column $1.7 \mu \mathrm{m}, 2.1 \times 100 \mathrm{~mm}$ type UPLC BEH C18 column (Waters Corp., Milford, CT, USA) was used for separating compounds. For analysis, $10 \mu \mathrm{L}$ of sample was injected, and the elution was completed in $15 \mathrm{~min}$ at $30^{\circ} \mathrm{C}$ with a sequence of linear gradients and isocratic flow rates of $0.42 \mathrm{~mL} \mathrm{~min}^{-1}$ of $\mathrm{A}(0.1 \%$ formic acid, $v / v)$ and solvent $\mathrm{B}(100 \%$ of acetonitrile) solvents: $0-12 \mathrm{~min}$ from $99 \%$ to $65 \%$ of $\mathrm{A}, 12.1-13.5 \mathrm{~min}$ from $65 \%$ to $0 \%$ of $\mathrm{A}$, then gradient was returned to $99 \%$ of A solvent to re-equilibrate the column for $15 \mathrm{~min}$. The mass spectrometer was performed within ESI-MS accurate mass experiments operated in negative-ion mode, set to the base peak intensity (BPI) chromatograms with scanning from $\mathrm{m} / \mathrm{z} 100-1500$ and the lock mass correction \pm 1.000 for the mass window. The optimized MS conditions were as follows: Cone voltage of $30 \mathrm{~V}$, capillary voltage of $2500 \mathrm{~V}$, argon as collision gas, with voltage ramping cycles from 0.3 to $2 \mathrm{~V}$, desolvation and source temperature were 300 and $100{ }^{\circ} \mathrm{C}$, respectively. Leucine enkephalin at a concentration of $500 \mathrm{pg} / \mu \mathrm{L}$ with [M - H] $]^{-}$ion at 554,2615 Da was used as the reference compound. The data obtained from LC-MS were subsequently entered into the MassLynx 4.0 ChromaLynx Application Manager software (Waters Corp., Milford, CT, USA). The PDA spectra were measured over the wavelength range of 200-800 nm in steps of $2 \mathrm{~nm}$. The calibration curves were made for the standard loganin ( $y=35595 x-64514$; $\left.r^{2}=0.9995\right)$ and loganic acid $\left(y=27901 x+108708 ; r^{2}=0.9994\right),($ at $240 \mathrm{~nm})$, for chlorogenic $(y=26754 x$ $\left.+172359 ; r^{2}=0.9995\right)$, neochlorogenic $\left(y=30401 x+91716 ; r^{2}=0.9994\right)$, cryptochlorogenic $(y=30726 x$ $\left.+190297 ; r^{2}=0.9976\right), 3,5$-dicaffeoylquinic acids $\left(y=39233 x-360853 ; r^{2}=0.9994\right)($ at $320 \mathrm{~nm})$, and for luteolin-7-O-glucoside $\left(y=11211 x+498134 ; r^{2}=0.9835\right)$, apigenin-7-O-glucoside $(y=20768+121323 x$; $\left.r^{2}=0.9912\right)($ at $340 \mathrm{~nm}$ ) at concentrations ranging from 0.05 to $0.5 \mathrm{mg} / \mathrm{mL}$. Loganin and loganic acid were expressed as loganin and loganic acid, respectively, but the rest of the iridoids (sweroside, cantleyoside, and sylvestroside III) were calculated as loganin compounds. Neochlorogenic acid was expressed as neochlorogenic acid, chlorogenic acid was expressed as chlorogenic acid, cryptochlorogenic acid was expressed as cryptochlorogenic acid, and 3,5-dicaffeoylquinic and caffeoylquinic acids and their isomers were expressed as 3,5-dicaffeoylquinic acid. Apigenin compounds were expressed as apigenin-7-O-glucoside, and luteolin -C-D-glucopiranoside was expressed as luteolin-7-O-glucoside. The results were expressed as milligrams per $\mathrm{g} d \mathrm{w}$.

\subsection{Antimicrobial Activity}

In vitro antimicrobial studies were carried out against 5 bacterial strains, namely Bacillus subtilis B5, Escherichia coli ATCC 10536, Pseudomonas aeruginosa DSM 939, Pseudomonas fluorescens W1, Staphylococcus aureus DSM 799. Additionally, activity of extract was analyzed against selected yeast: Candida famata AII4b, Candida tropicalis ATCC 60557, Candida sphaerica FII7a, Saccharomyces cerevisiae SV30, Yarrowia lipolytica PII6a. All bacterial strains and yeast were from the collection at the Department of Biotechnology and Food Microbiology, Wrocław University of Environmental and Life Sciences. Dried powdered samples of roots and leaves were extracted with aqueous solution. The extraction was performed twice via an incubation for $20 \mathrm{~min}$ under sonication with shaking (Sonic 6D, Polsonic, Warsaw, Poland), then sample was centrifuged at $19,000 \times g$ for $15 \mathrm{~min}$, and the supernatant was used for analysis. Extractions were carried out in triplicate.

3.5.1. Agar Diffusion Method: The Effects of Water Extracts from Leaves and Root on Growth of Bacteria and Yeast

Inoculum preparation. Each bacterial strain was sub-cultured in medium NB (Merck, Darmstadt, Germany) at $30^{\circ} \mathrm{C}$ for $24 \mathrm{~h}$. After centrifugation (10,000 $\mathrm{g}$ rpm; $20 \mathrm{~min}$; Isolab D2012, Laborgeräte 
$\mathrm{GmbH}$, Eschau, Germany), bacterial cells were washed twice, using sterile water, and suspended in fresh sterile NB medium. Absorbances were adjusted at $620 \mathrm{~nm}$ and diluted to attain viable cell count of $1 \times 10^{9} \mathrm{cfu} / \mathrm{mL}$ using a spectrophotometer (Smart Spec Plus, Biorad, Hercules, CA, USA) (optical density, $\left.\mathrm{OD}_{620}=1.5\right)$

Yeast were cultured in the YM broth, which consisted of $3 \mathrm{~g}$ yeast extract, $3 \mathrm{~g}$ malt extract, $5 \mathrm{~g}$ bacteriological peptone, and $10 \mathrm{~g}$ of glucose dissolved in $1 \mathrm{~L}$ of distilled water. The cultivations were conducted for $48 \mathrm{~h}$ in $0.3 \mathrm{~L}$ flasks containing $0.075 \mathrm{~L}$ medium on a rotary shaker (G10 Gyrotory Shaker, NewBrunswick-Scientific Co.; Edison, NJ, USA) at $160 \mathrm{rpm}$ and $25^{\circ} \mathrm{C}$. After centrifugation (7000 rpm; 20 min; Isolab D2012, Laborgeräte GmbH, Eschau Germany), yeast cells were washed two times and suspended in fresh sterile YM broth. The suspension was standardized with 2 McFarland turbidity standard (McFarland Standard, bioMerieux, Marcy l'Etoile, France) equal to $1 \times 10^{6} \mathrm{cfu} / \mathrm{mL}$.

One $\mathrm{mL}$ of bacterial suspension $\left(1 \times 10^{9}\right.$ cells $\left./ \mathrm{mL}\right)$ and $1 \mathrm{~mL}$ of yeast suspension $\left(1 \times 10^{6}\right.$ cells $\left./ \mathrm{mL}\right)$ were mixed with $20 \mathrm{~mL}$ melted $\left(45^{\circ} \mathrm{C}\right) \mathrm{NB}$-agar and YM-agar, respectively, and poured into Petri dishes.

The plates were kept in the fridge at $5{ }^{\circ} \mathrm{C}$ for $2 \mathrm{~h}$. To permit plant extract diffusion, they were then incubated at $30^{\circ} \mathrm{C}$ for $2-7$ days. The examinations were carried out in triplicate. The presence of inhibition (-) or intensive growth (+) zones were measured by Vernier caliper, recorded, and considered as indications of antibacterial activity. No effect was marked as (0).

\subsubsection{Well Diffusion Method}

Well diffusion method on NB-agar (Merck) was used for evaluating antibacterial activities of water extract from root and leaves. Under aseptic conditions, NB agar plates were inoculated by tested bacterial or yeast strain. Test samples $(50 \mu \mathrm{L})$ were added to each well with $6 \mathrm{~mm}$ diameter holes and incubated for $24-72 \mathrm{~h}$ at $30^{\circ} \mathrm{C}$. After this period, confluent bacterial or yeast growth was observed. The following control agents were positive control agents—oxytetracycline $(5 \mu \mathrm{g} / \mathrm{mL})$ (for bacteria) and cycloheximide $20 \mathrm{mg} / \mathrm{mL}$ (for yeasts).

\subsubsection{Spot Test}

The powder from leaves and roots of D. fullonum L. were spread onto the surface of the above media $(0.05 \mathrm{mg})$ using a sterile spatula. As a positive control, oxytetracycline crystals (bacteria) and cycloheximide (yeast) crystals were used.

\subsubsection{Growth in Bioscreen C Microbial Growth Analyzer}

The tests were performed in the automated Bioscreen C system (Automated Growth Curve Analysis System, Lab systems, Helsinki, Finland) according to the procedure described by Wróblewska et al. [52]. NB medium and water extracts from plants were filter sterilized using sterile, disposable syringe filters of $0.2 \mathrm{~mm}$ pore size $13 \mathrm{~mm}$ diameter. The bacterial inoculum was diluted in sterile deionized water to give a concentration of approximately $2^{\circ} \mathrm{McFarland}$. The working volume in the wells of the Bioscreen plate was $0.35 \mathrm{~mL}$, comprising $0.30 \mathrm{~mL}$ of culture medium with water plant extract and $0.05 \mathrm{~mL}$ of inoculum (final concentration $1 \times 10^{6}$ cells $/ \mathrm{mL}$ ). The temperature was controlled at $30^{\circ} \mathrm{C}$, and the optical density of the cell suspensions was measured automatically at $560 \mathrm{~nm}$ in regular intervals of $30 \mathrm{~min}$ for $50 \mathrm{~h}$. The cell cultures were automatically continuously shaken. Each culture was performed in 5 replications.

\subsection{Biological Activity}

The ORAC assay was determined following the method previously described by Ou et al. [53]. All samples were assayed in triplicate, and the results were expressed as mmol of Trolox per $100 \mathrm{~g}$ of $\mathrm{dw}$. The anti-acetylcholinesterase activity was measured as inhibition of acetylcholinesterase as reported previously by Wojdyło, Nowicka, and Babelewski [51]. All samples were performed in triplicate and the result was presented as $\%$ of inhibition. 


\subsection{Statistical Analysis}

Statistical analyses were performed with Statistica version 12.0 software package (StatSoft Inc., Tulsa, OK, USA). All data were presented as mean \pm standard deviation of three independent determinations and were subjected to a one-way analysis of variance (ANOVA) by Duncan's test, while post hoc test was used to compare the mean values.

\section{Conclusions}

The study provides a comprehensive summary of a specific bioactive profile of Dipsacus fullonum L. leaves and roots. In the leaves, the most abundant iridoids were cantleyoside and sylvestroside III, and in the roots cantleyoside and loganic acid were prevailing. Phenolic acid, chlorogenic acid, 3,5-dicaffeoylquinic acid, and apigenin-6-C-glucoside-7-O-glucoside were evenly distributed within the plants. Additionally, our analysis revealed that the leaves collected in the second year of vegetation contained two times more polyphenols than iridoids as compared with the first year. Finally, the roots contained more iridoids than leaves. Leaf extract showed stronger antioxidant activity, but roots exhibited higher antiacetylcholinesterase activity than leaves. Antibacterial activity against Staphylococcus aureus DSM 799 and Escherichia coli ATCC 10536 was only noted in root extract.

The study demonstrated that Dipsacus fullonum L. could be considered a natural source of bioactive compounds, particularly phenolics and iridoids, and confirmed its high potential for the pharmaceutical industry. Future studies focused on nutritional value and technological possibilities of using Dipsacus fullonum L. seem well deserved.

Author Contributions: Important contributions to design and in preparation of the manuscript: J.O., A.W., P.J. and P.N. Contributions to sample and analysis experiments: J.O., P.N., A.W., P.J. Analysis of the experimental data: J.O., A.W., P.N., P.J. Critical revision for important intellectual content: J.O. and A.W. All authors have read and agreed to the published version of the manuscript.

Funding: Publication supported by Wroclaw Centre of Biotechnology, program The Leading National Research Centre (KNOW) for years 2014-2018.

Acknowledgments: The publication was the result of the activity of the research group "Plants4food" (A.W. and P.N.).

Conflicts of Interest: The authors declare no conflict of interest.

\section{References}

1. Kaiser, A.; Carle, R.; Kammerer, D.R. Effects of blanching on polyphenol stability of innovative paste-like parsley (Petroselinum crispum (Mill.) Nym ex A. W. Hill) and marjoram (Origanum majorana L.) products. Food Chem. 2013, 138, 1648-1656. [CrossRef] [PubMed]

2. Ferlemi, A.V.; Lamari, F.N. Berry leaves: An alternative source of bioactive natural products of nutritional and medicinal value. Antioxidants 2016, 5, 17. [CrossRef] [PubMed]

3. World Health Organization. Legal Status of Traditional Medicine and Complementary/Alternative Medicine: Worldwide Review; WHO: Geneva, Switzerland, 2001.

4. Chandrasekara, A.; Shahidi, F. Herbal beverages: Bioactive compounds and their role in disease risk reduction-A review. J. Tradit. Complement. Med. 2018, 8, 451-458. [CrossRef]

5. Tabart, J.; Franck, T.; Kevers, C.; Pincemail, J.; Serteyn, D.; Defraigne, J.O.; Dommes, J. Antioxidant and anti-inflammatory activities of Ribes nigrum extracts. Food Chem. 2012, 131, 1116-1122. [CrossRef]

6. Grayer, R.J.; Kokubun, T. Plant-fungal interactions: The search for phytoalexins and other antifungal compounds from higher plants. Phytochemistry 2001, 56, 253-263. [CrossRef]

7. Pan, J.; Yi, X.; Wang, Y.; Chen, G.; He, X. Benzophenones from mango leaves exhibit $\alpha$-glucosidase and NO anhibitory activities. J. Agric. Food Chem. 2016, 64, 7475-7480. [CrossRef] 
8. Hämäläinen, M.; Nieminen, R.; Vuorela, P.; Heinonen, M.; Moilanen, E. Anti-inflammatory effects of flavonoids: Genistein, kaempferol, quercetin, and daidzein inhibit STAT-1 and NF-kB activations, whereas flavone, isorhamnetin, naringenin, and pelargonidin inhibit only NF-kB activation along with their inhibitory effect on iNOS expression and NO production in activated macrophages. Med. Inflamm. 2007, 2007, 45673. [CrossRef]

9. Dinda, B.; Debnath, S.; Harigaya, Y. Naturally occurring secoiridoids and bioactivity of naturally occurring iridoids and secoiridoids. A review, part 2. Chem. Pharm. Bull. 2007, 55, 689-728. [CrossRef]

10. Ghisalberti, E.L. Biological and pharmacological activity of naturally occurring iridoids and secoiridoids. Phytomedicine 1998, 5, 147-163. [CrossRef]

11. Ramírez-Cisneros, M.A.; Rios, M.Y.; Aguilar-Guadarrama, A.B.; Rao, P.P.N.; Aburto-Amar, R.; Rodríguez-López, V. In vitro COX-1 and COX-2 enzyme inhibitory activities of iridoids from Penstemon barbatus, Castilleja tenuiflora, Cresentiaalata and Vitex mollis. Bioorg. Med. Chem. Lett. 2015, 25, 4505-4508. [CrossRef]

12. Simmons, D.L.; Botting, R.M.; Hla, T. Cyclooxygenase isozymes: The biology of prostaglandin synthesis and inhibition. Pharmacol. Rev. 2004, 56, 387. [CrossRef] [PubMed]

13. Pieri, V.; Schwaiger, S.; Ellmerer, E.P.; Stuppner, H. Iridoid glycosides from the leaves of Sambucus ebulus. J. Nat. Prod. 2009, 72, 1798-1803. [CrossRef] [PubMed]

14. Liebold, T.; Straubinger, R.; Rauwald, H. Growth inhibiting activity of lipophilic extracts from Dipsacus sylvestris Huds. Roots against Borrelia burgdorferi s. s. in vitro. Pharmazie 2011, 66, 628-630. [PubMed]

15. Zhao, Y.-M.; Shi, Y.P. Phytochemicals and biological activities of Dipsacus species. Chem. Biodivers. 2011, 8, 414-430. [CrossRef] [PubMed]

16. Brorson, $\varnothing$.; Brorson, S.H. An in vitro study of the activity of telithromycin against mobile and cystic forms of Borrelia afzelii. Infection 2006, 34, 26-28. [CrossRef]

17. Jensen, S.R.; Lyse-Petersen, S.E.; Nielsen, B.J. Novel bis-iridoid glucosides from Dipsacus sylvestris. Phytochemistry 1979, 18, 273-277. [CrossRef]

18. Tomassini, L.; Foddai, S.; Nicoletti, M. Iridoids from Dipsacus ferox (Dipsacaceae). Biochem. Syst. Ecol. 2004, 32, 1083-1085. [CrossRef]

19. Tomita, H.; Mouri, Y. An iridoid glucoside from Dipsacus asperoides. Phytochemistry 1996, 42, $239-240$. [CrossRef]

20. Linga, Y.; Liu, K.; Zhang, Q.; Liao, L.; Lu, Y. High performance liquid chromatography coupled to electrospray ionization and quadrupole time-of-flight-mass spectrometry as a powerful analytical strategy for systematic analysis and improved characterization of the major bioactive constituents from Radix Dipsaci. J. Pharm. Biomed. Anal. 2016, 98, 120-129.

21. Li, Y.; Zhang, J.J.; Xu, D.-P.; Zhou, T.; Zhou, Y.; Li, S.; Li, H.-B. Bioactivities and health benefits of wild fruits. Int. J. Mol. Sci. 2016, 17, 1258. [CrossRef]

22. Kocsis, J.D.; László, F.; Szabó, B.P. New Bis-Iridoids from Dipsacusl aciniatus. J. Nat. Prod. 1993, 56, $1486-1499$. [CrossRef]

23. Oszmiański, J.; Kucharska, A. Effect of pre-treatment of blue honeysuckle berries on bioactive iridoid content. Food Chem. 2018, 240, 1087-1091. [CrossRef] [PubMed]

24. Cao, G.; Zhang, Y.; Feng, J.; Cai, H.; Zhang, C.; Ding, M.; Cong, X. Rapid and sensitive assay for determining the main components in processed Fructus corni by UPLC-Q-TOF-MS. Chromatographia 2011, 73, 135-141. [CrossRef]

25. Tian, X.-Y.; Wang, Y.-H.; Liu, H.-Y.; Yu, S.-S.; Fang, W.-S. On the chemical constituents of Dipsacus asper. Chem. Pharm. Bull. 2007, 55, 1677-1681. [CrossRef] [PubMed]

26. Ji, D.; Zhang, C.; Li, J.; Yang, H.; Shen, J.; Yang, Z. A New iridoid glycoside from the Roots of Dipsacus asper. Molecules 2012, 17, 1419-1424. [CrossRef]

27. Kucharska, A.; Szumny, A.; Sokół-Łętowska, A.; Piórecki, N.; Klymenko, S.V. Iridoids and anthocyanins in cornelian cherry (Cornus mas L.) cultivars. J. Food Compos. Anal. 2015, 40, 95-102. [CrossRef]

28. Hung, T.M.; Na, M.K.; Thuong, P.T.; Su, N.D.; Sok, D.E.; Song, K.S.; Seong, Y.H.; Bae, K.H. Antioxidant activity of caffeoyl quinic acid derivatives from the roots of Dipsacus asper Wall. J. Ethnopharmacol. 2006, 108, 188-192. [CrossRef]

29. Kowalczyk, A.; Krzyżanowska, J. Preliminary antifungal activity of some Dipsacaceae family plants. Herba. Pol. 1999, 2, 101-107. 
30. Yang, H.B.; Feng, X.; Xu, J.; Lei, H.; Zhang, L. Multi-component HPLC analysis and antioxidant activity characterization of extracts from Dipsacus sativus (Linn.) Honck. Int. J. Food Prop. 2016, 19, 1000-1006. [CrossRef]

31. Sożanski, T.; Kucharska, A.Z.; Rapak, A.; Szumny, D.; Trocha, M.; Merwid-Ląd, A.; Dzimira, S.; Piasecki, T.; Piórecki, N.; Magdalan, J.; et al. Iridoid-loganic acid versus anthocyanins from the Cornus mas fruits (Cornelian cherry): Common and different effects on diet-induced atherosclerosis, PPARs expression and inflammation. Atherosclerosis 2016, 254, 151-160. [CrossRef]

32. Takamura, C.; Hirata, T.; Ueda, T.; Ono, M.; Miyashita, H.; Ikeda, T.; Nohara, T. Iridoids from the Green Leaves of Eucommia ulmoides. J. Nat. Prod. 2007, 70, 1312-1316. [CrossRef] [PubMed]

33. Shin, H.S.; Satsu, H.; Bae, M.J.; Zhao, Z.; Ogiwara, H.; Totsuka, M.; Shimizu, M. Anti-inflammatory effect of chlorogenic acid on the IL-8 production in Caco-2 cells and the dextran sulphate sodium-induced colitis symptoms in C57BL/6 mice. Food Chem. 2015, 168, 167-175. [CrossRef] [PubMed]

34. Teleszko, M.; Wojdyło, A. Comparison of phenolic compounds and antioxidant potential between selected edible fruits and their leaves. J. Funct. Foods 2015, 14, 736-746. [CrossRef]

35. Tandon, S.; Garg, G.; Adarwal, R.; Sand, N.K. Qualitative analysis of phenolic constituents from Ajuga and Teucrium leaves and roots. J. Nat. Prod. Biomed. Res. 2016, 2, 1-3.

36. Oszmiański, J.; Wojdyło, A.; Lamer-Zarawska, E.; Świąder, K. Antioxidant tannins from Rosaceae plant roots. Food Chem. 2007, 100, 579-583. [CrossRef]

37. Sánchez-Salcedo, E.M.; Mena, P.; García-Viguera, C.; Hernández, F.; Martínez, J.J. (Poly) phenolic compounds and antioxidant activity of white (Morus alba) and black (Morus nigra) mulberry leaves: Their potential for new products rich in phytochemicals. J. Funct. Foods 2015, 18, 1039-1046. [CrossRef]

38. Paliyath, G.; Pinhero, R.G.; Rao, M.V.; Murr, D.P.; Fletcher, R.A. Changes in activities of antioxidant enzymes and their relationship to genetic and paclobutrazol-induced chilling tolerance in maize seedlings. Plant Physiol. 1997, 114, 695-704.

39. Tattini, M.; Galardi, C.; Pinelli, P.; Massai, R.; Remorini, D.; Aggati, G. Differential accumulation of flavonoids and hydroxycinnamates in leaves of Ligustrum vulgare under excess light and drought stress. New Phytol. 2004, 163, 547-561. [CrossRef]

40. Wang, S.Y.; Lin, H.S. Antioxidant activity in fruits and leaves of blackberry, raspberry and strawberry with cultivar and development stage. J. Agric. Food Chem. 2000, 48, 140-146. [CrossRef]

41. Stanković, N.; Mihajilov-Krstev, T.; Zlatkovic, B.; Stankov-Jovanovic, V.; Mitic, V.; Jovic, J.; Comic, L.; Kocic, B.; Bernstein, N. Antibacterial and antioxidant activity of traditional medicinal plants from the Balkan Peninsula. NJAS Wagening. J. Life Sci. 2016, 78, 21-28. [CrossRef]

42. Sharifi-Rad, J.; Sureda, A.; Tenore, G.C.; Daglia, M.; Sharifi-Rad, M.; Valussi, M.; Tundis, R.; Sharifi-Rad, M.; Loizzo, M.R.; Ademiluyi, A.O.; et al. Biological activities of essential oils: From plant chemoecology to traditional healing systems. Molecules 2017, 22, 70. [CrossRef] [PubMed]

43. Osawa, K.; Yasuda, H.; Maruyama, T.; Morita, H.; Takeya, K.; Itokawa, H. Isoflavanones from the heartwood of Swartzia polyphylla and their antibacterial activity against cariogenic bacteria. Chem. Pharm. Bull. 1992, 40, 2970-2974. [CrossRef] [PubMed]

44. Ohemeng, K.A.; Schwender, C.F.; Fu, K.P.; Barrett, J.F. DNA gyrase inhibitory and antibacterial activity of some flavones. Bioorg. Med. Chem. Lett. 1993, 3, 225-230. [CrossRef]

45. Bernard, F.X.; Sable, S.; Cameron, B.; Provost, J.; Desnottes, J.F.; Crouzet, J.; Blanche, F. Glycosylated flavones as selective inhibitors of topoisomerase IV. Antimicrob. Agents Chemother. 1997, 41, 992-998. [CrossRef]

46. Seow, Y.X.; Yeo, C.R.; Chung, H.L.; Yuk, H.-G. Plant essential oils as active anti- microbial agents. Crit. Rev. Food Sci. Nutr. 2014, 54, 625-644. [CrossRef]

47. Aghraz, A.; Benameur, Q.; Gervasi, T.; Ait dra, L.; Ben-Mahdi, M.H.; Larhsini, M.; Markouk, M.; Cicero, N. Antibacterial activity of Cladanthus arabicus and Bubonium imbricatum essential oils alone and in combination with conventional antibiotics against Enterobacteriaceae isolate. Lett. Appl. Microbiol. 2018, 67, 175-182. [CrossRef]

48. Pacifico, S.; D’Abrosca, B.; Pascarella, M.T.; Letizia, M.; Uzzo, P.; Piscopo, V.; Fiorentino, A. Antioxidant efficacy of iridoid and phenylethanoid glycosides from the medicinal plant Teucrium chamaedrisin cell-free systems. Med. Chem. 2009, 17, 6173-6179. [CrossRef]

49. Hasbal, G.; Yilmaz-Ozden, T.; Can, A. Antioxidant and antiacetylcholinesterase activities of Sorbus torminalis (L.) Crantz (wild service tree) fruits. J. Food Drug Anal. 2015, 23, 57-62. [CrossRef] 
50. Bivar Roseiro, L.; Rauter, A.P.; Mourato Serralheiro, M.L. Polyphenols as acetylcholinesterase inhibitors: Structural specificity and impact on human disease. Nutr. Aging 2012, 1,99-111. [CrossRef]

51. Wojdyło, A.; Nowicka, P.; Babelewski, P. Phenolic and carotenoid profile of new goji cultivars and their anti-hyperglycemic, anti-aging and antioxidant properties. J. Funct. Foods 2018, 48, 632-642. [CrossRef]

52. Wróblewska, K.; Szumny, A.; Żarowska, B.; Kromer, K.; Dębicz, R.; Fabian, S. Impact of mulching on growth essential oil composition and its biological activity in Monarda didyma L. Ind. Crop Prod. 2019, 129, 299-308. [CrossRef]

53. Ou, B.; Huang, D.; Hampsch-Woodill, M.; Flanagan, J.A.; Deemer, E.K. Analysis of antioxidant activities of common vegetables employing oxygen radical absorbance capacity (ORAC) and ferric reducing antioxidant power (FRAP) assays: A comparative study. J. Agric. Food Chem. 2002, 50, 3122-3128. [CrossRef] [PubMed]

(C) 2020 by the authors. Licensee MDPI, Basel, Switzerland. This article is an open access article distributed under the terms and conditions of the Creative Commons Attribution (CC BY) license (http://creativecommons.org/licenses/by/4.0/). 